\title{
A Study on Preventing Spontaneous Combustion of Residual Coal in a Coal Mine Goaf
}

\author{
Yongjun Wang, ${ }^{1}$ Xiaoming Zhang, ${ }^{2}$ Yuichi Sugai, ${ }^{1}$ and Kyuro Sasaki ${ }^{1}$ \\ ${ }^{1}$ Department of Earth Resources Engineering, Faculty of Engineering, Kyushu University, Fukuoka 819-0395, Japan \\ ${ }^{2}$ Institute of Engineering and Environment, Liaoning Technical University, Huludao 125000, China
}

Correspondence should be addressed to Yongjun Wang; yongjunwang2012@gmail.com

Received 29 December 2014; Accepted 6 March 2015

Academic Editor: Umberta Tinivella

Copyright (C) 2015 Yongjun Wang et al. This is an open access article distributed under the Creative Commons Attribution License, which permits unrestricted use, distribution, and reproduction in any medium, provided the original work is properly cited.

The effectiveness of grouting scheme has been simulated to prevent the coal spontaneous combustion at a goaf in Haizi Colliery, China. The colliery has been operated for long period over 27 years and has a complex ventilation network including airflow leakages which could possibly lead to the spontaneous combustion of coal at goafs. Firstly, the mine ventilation simulator MIVENA was used to analyze the mine ventilation network airflows to control airflows in and out of working faces and goafs. As the second approach, numerical simulations were carried by the simulator FLUENT in order to predict spontaneous combustion of residual coal with leakage flow in the \#3205 goaf. It was cleared that the goaf can be divided into three zones based on oxygen concentration in the goaf area. Finally, the numerical simulation results show that the slurry grouting method is able to be an effective and economical method by reducing porosity in the goaf area to prevent spontaneous combustion of residual coal.

\section{Introduction}

It is well known that the key area relating to underground coal mine fire is goaf areas where there exists a potential to induce spontaneous combustion of residual coal in the goaf areas. According to the statistics of Chinese coal production, $90 \%$ of total production coal is produced by underground mines, and there are around 600 state-owned key coalmines of which $25.1 \%$ are highly gassy mines and $17 \%$ are gas outburst mines, approximately [1]. In Chinese underground coal mines, serious accidents occurred especially in last ten years. Since they produced a large amount of coal meets domestic demand, it resulted in insufficient effort to keep safety operations at working faces and goaf areas. In particular, most of the accidents were directly or indirectly related to coal spontaneous combustion in goaf areas.

Qi and Chen (2009) [2] studied the distributing condition of abutment pressure and air flowing state in goaf and then presented the theoretical formula to predict airflow velocity in goaf area and the spontaneous combustion zone where airflow velocity is less than $0.24 \mathrm{~m} / \mathrm{min}$. Pan et al. (2013) [3] analyzed a goaf and divided it into the three zones related to coal spontaneous combustion using with distribution of $\mathrm{O}_{2}$ and $\mathrm{CO}$ concentration. They classified the goaf area to radiating and asphyxiation zones by $\mathrm{O}_{2}$ concentrations larger than $18 \%$ and less than $7 \%$, respectively.

In this research, a preventing method for spontaneous combustion of residual coal at a goaf in Haizi Colliery has been studied, because it is a typical lignite coal mine in China and has a potential to get spontaneous combustion due to fusain existing in coal beds [4].

As shown in Figure 1, the Haizi Colliery's mine area is nearly $6.44 \mathrm{~km}^{2}$ consisting of 1,200 to 5,200 $\mathrm{m}$ along the strike and 0 to $1,700 \mathrm{~m}$ in tendency. Its coal seams are cleft by three normal faults that formed an isolated block area like a triangle coal-bearing zone. The current level that operates working faces is $-320 \mathrm{~m}$ from the surface. Average self-ignition point of the produced lignite coal is $275^{\circ} \mathrm{C}$. And the elapsed time after contacting air to spontaneous combustion in a pail has been estimated as roughly 1 to 1.5 month [5]. Based on the mine's operation record during 2002 to 2013, spontaneous combustion phenomenon has been frequently observed at working faces. The characteristics of Haizi coal are listed in Table 1. 


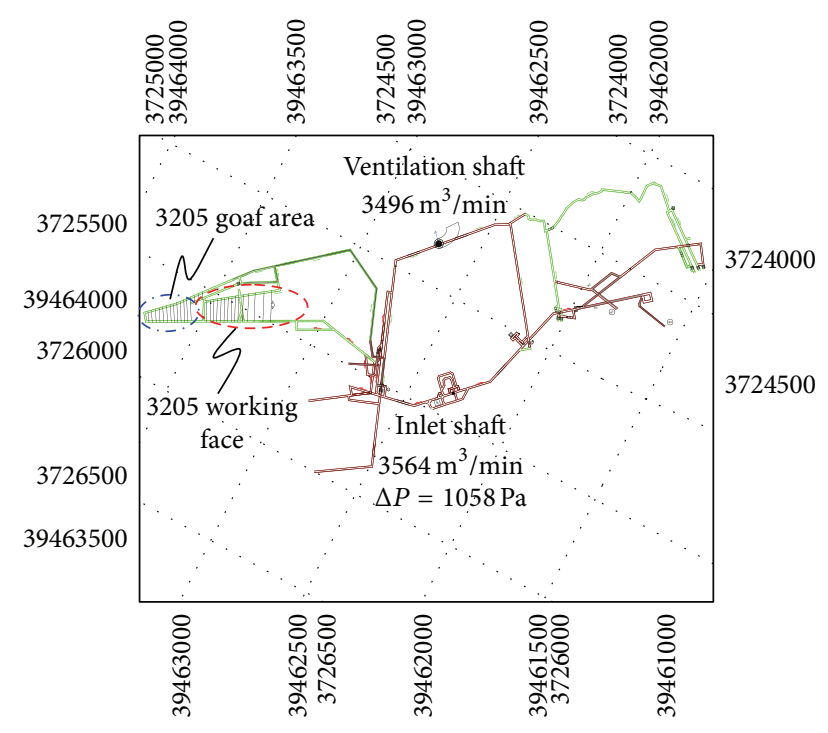

The ventilation system of west part in Haizi Colliery

$\begin{array}{rll}\longrightarrow \text { Inlet } & \text { Door } \\ \text { Outlet } & \text { A.C. door } \\ \text { Auxiliary fan } & \text { Stopping } \\ \text { Airtight wall } & \text { Main fan } & \text { Powder magazine } \\ \text { I Regulator } & \text { Palisade } \\ \text { 1031 Cutting face } & \text { Pump }\end{array}$

Figure 1: Plan of mining in Haizi coal mine.

TABLE 1: Density and proximate analysis of Haizi Colliery.

\begin{tabular}{lcccc}
\hline $\begin{array}{l}\text { Density } \\
\left(\mathrm{kg} / \mathrm{cm}^{3}\right)\end{array}$ & $\begin{array}{c}\text { Fixed carbon } \\
(\%)\end{array}$ & $\begin{array}{c}\text { Ash } \\
(\%)\end{array}$ & $\begin{array}{c}\text { Volatile matter } \\
(\%)\end{array}$ & $\begin{array}{c}\text { Moisture } \\
(\%)\end{array}$ \\
\hline 1.29 & 47.51 & 5.23 & 35.07 & 11.6 \\
\hline
\end{tabular}

In this study, as the first step, authors have analyzed ventilation network airflows in the mine using the simulator MIVENA [6], especially pressure drop at a working face to control leakage airflow into a goaf area. The FLUENT was also used to simulate leakage flow in the goaf area with comparison monitoring data by the tube bundle gas monitoring system. Finally the effectiveness of slurry grout injection into the goaf area has been investigated as an economical method preventing spontaneous combustion of residual coal in the goaf.

\section{Mine Ventilation Network Analysis}

In the Haizi Colliery, the centralized ventilation system is used with a main intake shaft for fresh ventilation air and an exhausting shaft utilized only for exhausting airflow. The intake shaft is $6 \mathrm{~m}$ in diameter $\left(28.3 \mathrm{~m}^{2}\right.$ in sectional area) and also is used for coal elevating and hoisting workers, while the exhaust shaft is $9.6 \mathrm{~m}^{2}$ in sectional area. Two main centrifugal fans, of which one is running and other is standby, were equipped to provide adequate ventilation capabilities.

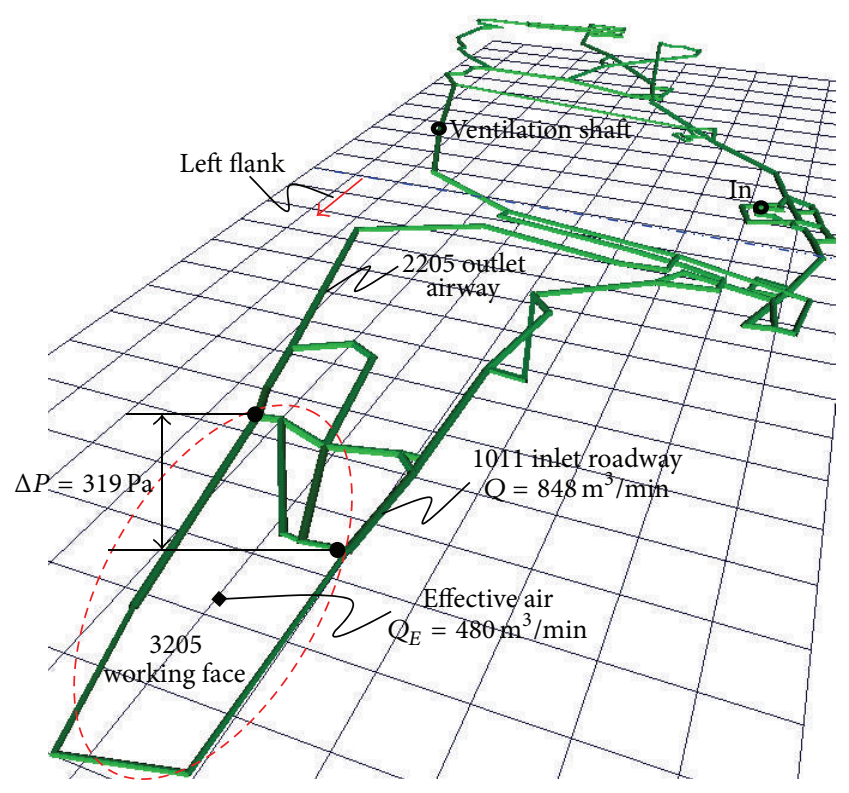

FIGURE 2: Three-dimensional network airways diagram provided by the MIVENA system.

A $220 \mathrm{~kW}$ motor operates each fan with $740 \mathrm{rpm}$ in rotating speed at an acceptable efficiency. The total intake airflow $Q=$ $3564 \mathrm{~m}^{3} / \mathrm{min}$ operated by total pressure loss $\Delta P=1058 \mathrm{~Pa}$.

In the present study, the mine ventilation network simulator MIVENA [6] has been applied to predict airflows and ventilation characteristics based on the network data (see Figure 2). In particular, the airflow around the \#3205 working face, that is fully-mechanized coal cutting faces [7], was focused by changing conditions with working face operation. After that, the simulated data was used to control airflows in the working face considering whole ventilation airflows in the network.

Based on the Chinese safety regulations [8] for coal mine ventilation, airflow velocity must satisfy the range of $0.25 \mathrm{~m} / \mathrm{s}$ to $4 \mathrm{~m} / \mathrm{s}$. Herein, Haizi Colliery evaluated air quantity through the goaf was $480 \mathrm{~m}^{3} / \mathrm{min}$ that meets the regulation mentioned above, because the air leakage was estimated as $368 \mathrm{~m}^{3} / \mathrm{min}$ (see Figure 2). The problem which was found was that many bypass or shortcut airways are existing at the bottom of heading with relatively large ventilation resistance in the left flank. The numerical simulations were carried for the ventilation cases with applying several useful methods to solve the problem. Based on the simulation results, the effective solution was to add an additional intake airway newly excavated in this area, because the new airway can contribute to decrease of $30 \%$ of airflow resistance at the \#3205 working face $5 \mathrm{~m}$ in width. It was predicted that the pressure drop decreases from $319 \mathrm{~Pa}$ to $270 \mathrm{~Pa}$ at the face; therefore it was also expected to be easier to control airflow leakage into the goaf area than before.

By using the procedure mentioned above, air leakage can be reduced to $200 \mathrm{~m}^{3} / \mathrm{min}$ from $338 \mathrm{~m}^{3} / \mathrm{min}$ at the $\# 3205$ working face. On the other hand, at working faces after excavation (such as \#2207 and \#1709 working faces), stopping 
TABLE 2: Chinese safety standards for divided goaf zones [8].

\begin{tabular}{lccc}
\hline Zone & Oxygen concentration & Airflow velocity & Temperature gradient $d \theta / d t$ \\
\hline Radiating & - & $V>0.02 \mathrm{~m} / \mathrm{s}$ & - \\
Oxidized & $\mathrm{O}_{2} \geq 8 \%$ & $0.02 \mathrm{~m} / \mathrm{s} \geq V \geq 0.001 \mathrm{~m} / \mathrm{s}$ & $d \theta / d t>1^{\circ} \mathrm{C} /$ day \\
Asphyxiation & $\mathrm{O}_{2}<8 \%$ & $V<0.001 \mathrm{~m} / \mathrm{s}$ & - \\
\hline
\end{tabular}

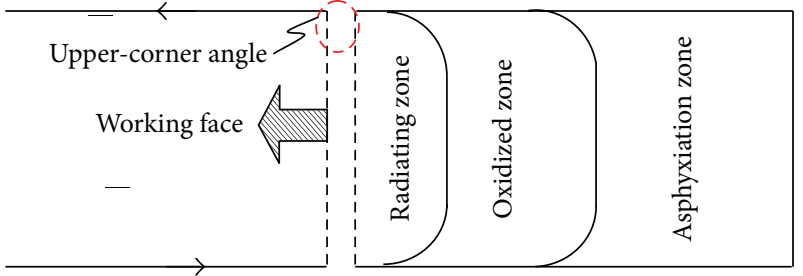

FIGURE 3: Schematic of three zones in the goaf.

walls were built immediately to prevent air leakage into goaf areas and to improve effectiveness of fresh-air utilization in the mine. After finishing optimizing mine ventilation airflows and pressure drop around working faces, authors focused on analyzing the goaf area and preventing spontaneous combustion of residual coal in the goaf.

\section{Three Zones at Goaf}

With the working face advancing, the state of goaf area changing step by step. Air leakage at the working faces supplies oxygen to the residual coal in the goaf area and coal seams close to the goaf, and it may lead coal spontaneous combustion in the goaf area classified into three zones that are radiating, oxidized, and asphyxiation zones as shown in Figure 3 [9-13]. These three zones can be characterized by flow velocity of air leakage $(V)$, oxygen concentration in the goaf area, and rate of temperature rise that are evaluated by the method defined in the Coal Mine Safety Regulation of China [8] as in Table 2.

3.1. Oxygen Concentration Detection in Goaf. The tube bundle gas monitoring system, shown in Figure 4, has been used to monitor the coal spontaneous combustion process in the goaf, continuously. It can detect the early stage of coal spontaneous combustion based on monitoring oxidation products, such as $\mathrm{CO}$, and then make an alarm to the mine engineers [14-16]. At the \#3205 face, gas sample is sucked into the tube bundle with an air pump. Numerous gas contents, such as $\mathrm{O}_{2}, \mathrm{~N}_{2}, \mathrm{CO}, \mathrm{CH}_{4}, \mathrm{CO}_{2}, \mathrm{C}_{2} \mathrm{H}_{4}, \mathrm{C}_{2} \mathrm{H}_{6}$, and so forth, are measured to detect the spontaneous combustion of coal at the monitoring spot. Gas concentration changes and distribution in the goaf area were used to make division into three zones in the goaf area, and its pros and cons were discussed to control the spontaneous combustion of coal [17].

About 50 gas monitoring points are installed in the underground, especially in the goaf areas by the monitoring system shown in Figure 5. Using continuous monitoring of

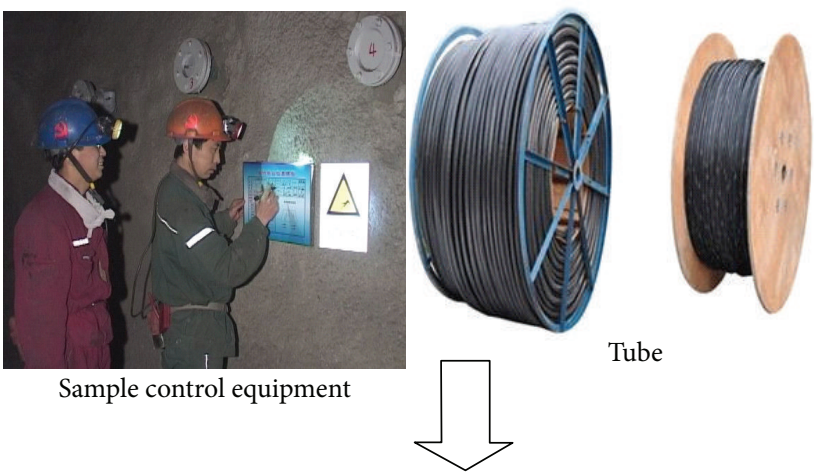

Analysis and monitor system

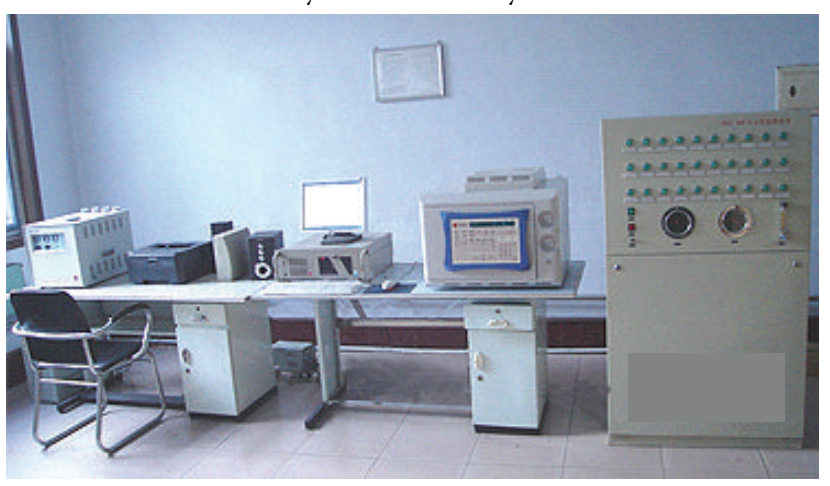

FIgURE 4: The tube bundle gas monitoring system for goaf area in the Haizi Colliery (December 2013).

gas compositions during three months, it was analyzed to pick up useful information on detecting spontaneous combustion.

The measured distribution of oxygen concentration in the goaf area is shown in Figure 6 where the horizontal axis is the distance along the \#3205 working face from its upstream corner and the vertical axis is distance from working face in the goaf. The contour lines of oxygen concentration were drawn by cubic spline function fitting the limited monitoring data (around 30). There is a relatively higher temperature range in the goaf area where $\mathrm{O}_{2}$ concentration was over $10 \%$ compared with others of which oxygen concentration is not up to this critical circumscription. Therefore, the goaf area can be divided into two zones of which boundary is the contour line of $10 \%$ concentration of oxygen. The determination of boundary line between the oxidized and asphyxiation zones in the goaf was relatively easy using the oxygen concentration curves, while that of the radiating zone boundary was difficult due to high oxygen concentration range close to $21 \%$ of air. The oxidized zone of which $\mathrm{O}_{2}$ concentration is over $10 \%$ shows a possibility to start spontaneous combustion in a few 


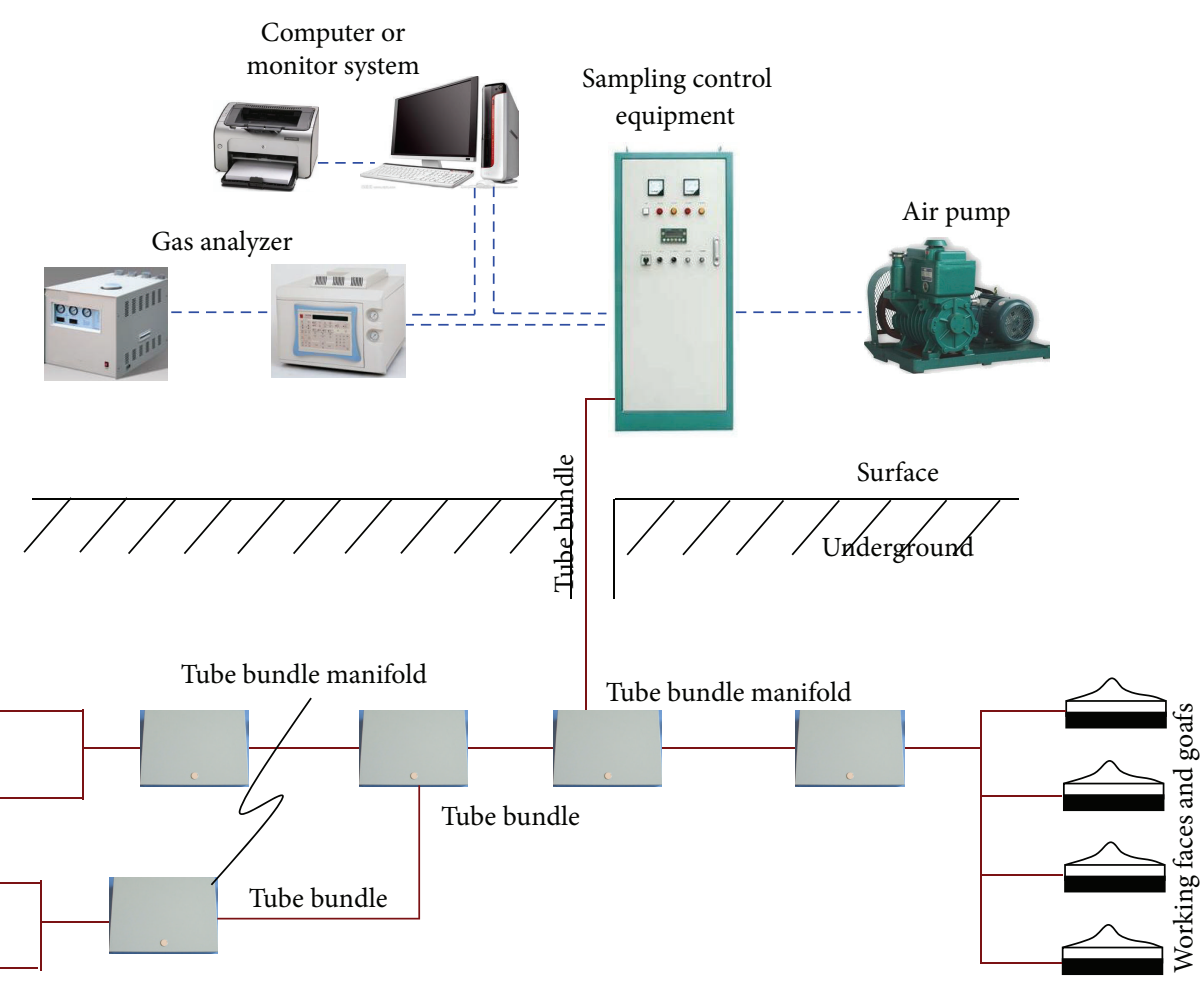

FIgURE 5: Schematic of the tube bundle gas monitoring system.

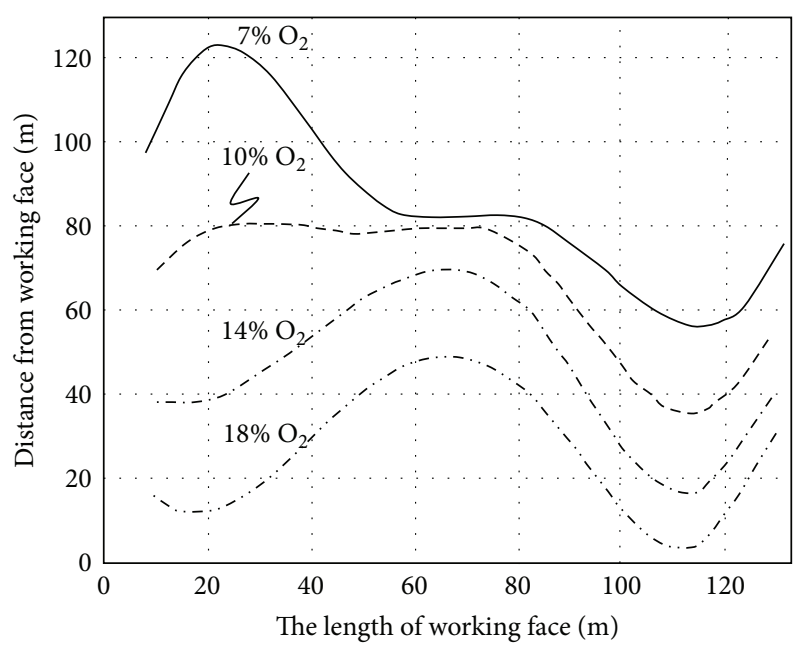

FIGURE 6: Distribution of oxygen concentration in 3205 goaf area (by Measurement, December 2013).

days [18]; however, the other zones showed a stable condition in temperature.

It has been confirmed from those results that measurements of oxygen concentration in a goaf are the most effective method to evaluate the potential of spontaneous combustion of residual coal.
3.2. Goaf Air Flow Simulation. The numerical simulator FULENT is an effective tool to investigate spontaneous combustion of coal in the goaf area, because monitoring data are limited to reproduce completely its heating process because spontaneous combustion is comprehensible phenomena including many physical and chemical parameters. As described in previous chapter, the radiating zone boundary is difficult to determine by using the oxygen distribution curve. In this research, the numerical simulation by FLUENT $[19,20]$ was taken into account to assist in drawing the boundary.

In the model for present 2-dimensional numerical simulations by FLUENT, the goaf was assumed as a zone of porous media composed filled with collapsed rock and unmined coal. At first, values of goaf porosity and differential pressure are required to simulate the airflow leakage along the working face. In the present study, uniform permeability was given for the gob area based on the measured data [21] and the observations at the mine site. The goaf average porosity was set as 0.3 in goaf according to the empirical formula and measured data [22]. On the other hand, oxygen concentration of $10 \% \mathrm{O}_{2}$ was used for compacted area based on the gas monitoring data recorded by the tube bundle system. The airflow is leaked through a working face into goaf area [23]. Furthermore, airflow in the goaf was treated as laminar flow expressed by Darcy's law [24]. Based on the monitoring data, the numerical simulation results by the ventilation simulator MIVENA, inlet airflow, and its velocity into the \#3205 


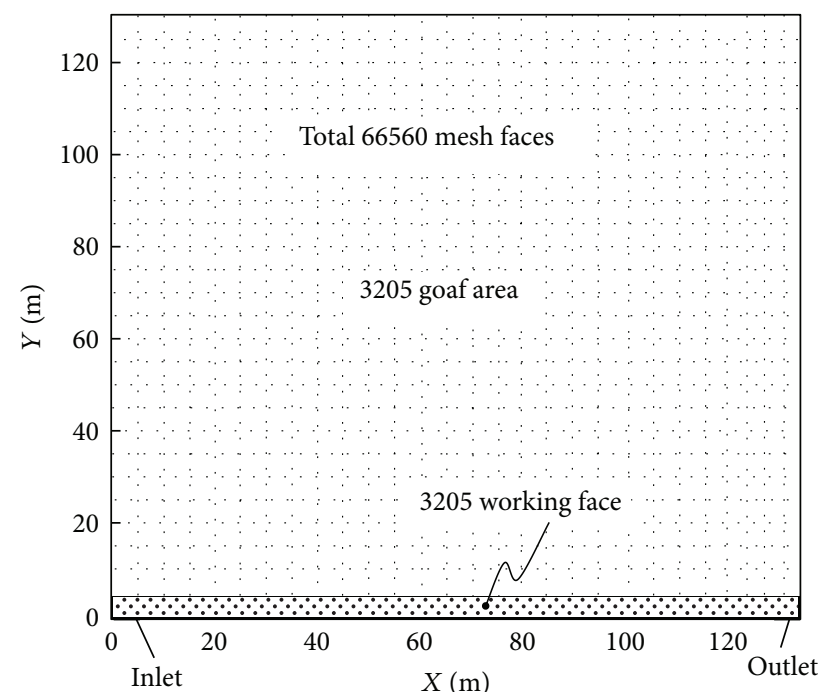

FIGURE 7: Gird block model of analysis area and definition of coordinate $(X, Y)$ (by Gambit).

face were evaluated as $852 \mathrm{~m}^{3} / \mathrm{min}$ and $1.3 \mathrm{~m} / \mathrm{s}$, respectively. Meanwhile, the differential pressure along the working face was simulated as $319 \mathrm{~Pa}$ (see Figure 2).

The numerical simulations on airflow leakage distribution in goaf area were carried out using with the above airflow conditions by the FULENT using the grid block size of $0.5 \mathrm{~m}$ $\times 0.5 \mathrm{~m}$ as shown in Figure 7 .

In the monitoring result shown in Figure 6, the area where air leakage velocity is over $0.001 \mathrm{~m} / \mathrm{s}$ corresponding to $7 \% \mathrm{O}_{2}$ is located 97 meters away from the \#1011 inlet roadway and $\# 2205$ outlet airway, while this area was $79 \mathrm{~m}$ away from the middle of \#3205 working face. The oxidation zone boundary is located at 74 to $92 \mathrm{~m}$ far from the working face. The pressure drop in the \#3205 working face that installed coal cutting machine, supports, and conveyors is much higher than that of the main airways. The measured pressure loss was $319 \mathrm{~Pa}$ along the working face $134 \mathrm{~m}$ in length. Airflow in the working face was treated as turbulent flow, because airflow velocity and roughness were large enough. In the FULENT, the standard $\kappa-\xi$ model which is a semiempirical model based on model transport equations for the turbulence kinetic energy $(k)$ and its dissipation rate $(\xi)$ was chosen to simulate the airflow in the working face.

Figure 8 shows the simulation result of the airflow velocity distribution in the goaf along the \#3205 working face. The flow quantity of air leakage into the goaf is increasing with the pressure drop along the working face. Thus ventilation control along the working face can reduce air leakage providing oxygen to residual coal in the goaf.

As shown in Figure 9, air leakage is observed at the zone located $20 \mathrm{~m}$ away from the \#3205 working face. And velocity is reduced with increasing distance from the 3205 working face. The working face $134 \mathrm{~m}$ in length was modeled between \#1011 inlet and \#2205 outlet airways.

The position showing the minimum airflow leakage velocity of $0.001 \mathrm{~m} / \mathrm{s}$ is located at the middle of \#3205 working

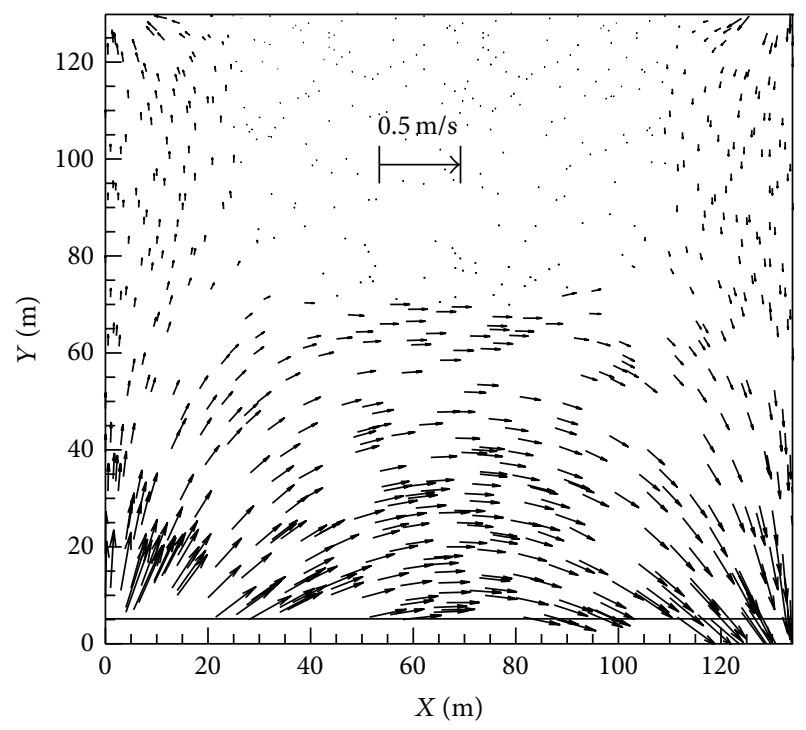

FIGURE 8: Air leakage flow velocity vector in goaf simulated by FLUENT.

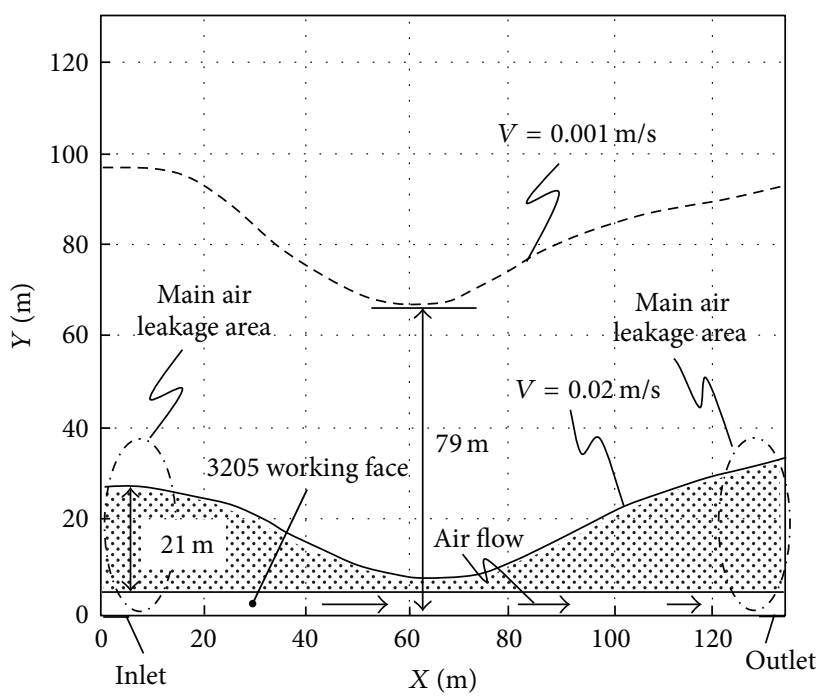

FIGURE 9: Contour lines of air leakage velocity in a goaf (unit: $\mathrm{m} / \mathrm{sec}$ ) simulated by FLUENT.

face. Figure 9 also indicates a larger amount of air leakage and higher velocity at inlet and exhaust ends in the \#3205 working face. In other words, the air leakage velocity equal to $1.2 \mathrm{~m} / \mathrm{min}(=0.02 \mathrm{~m} / \mathrm{s})$ boundary is 26 meters away from \#1011 inlet roadway and \#2205 outlet airway. Moreover, the gap between the boundary and middle part of \#3205 working face is 10 meters. Thus, installing air deflectors at uppercorner and down-corner angles are important to reduce the air leakage and its potential of spontaneous combustion of residual coal in the goaf.

The calculated width of oxidized zone boundary in the \#3205 working face is approximately 5 to $21 \mathrm{~m}$. Then, according to the oxygen concentration curves in goaf presented in Figure 6, the air leakage velocity of $0.001 \mathrm{~m} / \mathrm{s}$ shows 


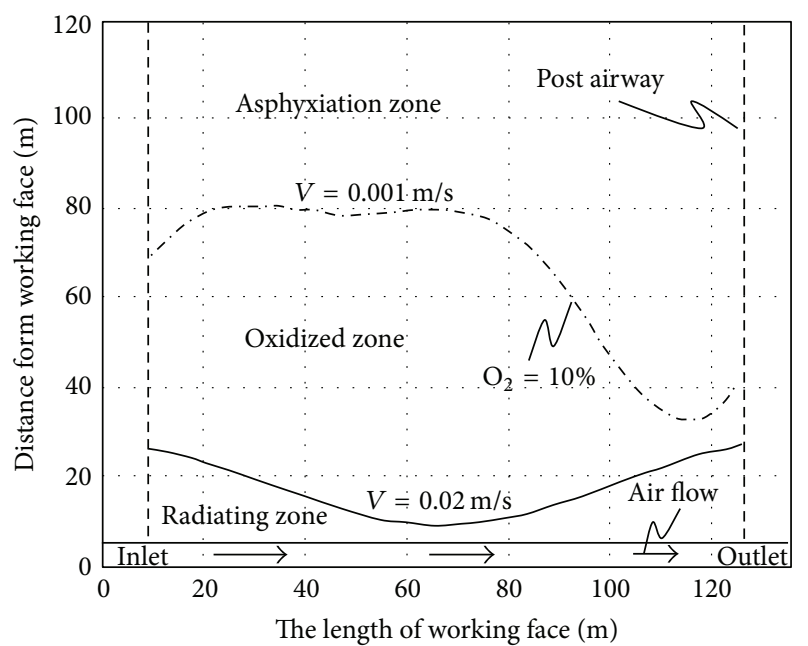

FIGURE 10: Schematic of "three zones" in goaf area.

approximately $7 \% \mathrm{O}_{2}$. The deep oxidation zone boundary is located at 74 to $92 \mathrm{~m}$ far from the \#3205 working face. Figure 10 shows the farthest boundary of the oxidation zone with $10 \% \mathrm{O}_{2}$ is located at 80 meters away from the \#3205 working face. However, the nearest one which is next to the radiating zone is about $30 \mathrm{~m}$ far from the \#3205 working face. By drawing the boundary lines, it is clear that the width of oxidation zone becomes narrower with increasing distance from both ends of the working face. At the same time, the radiating zone expands gradually from the center to both sides of the working face. The maximum temperature zone is located at $21 \mathrm{~m}$ away from the working face. These characteristics of three zones are important to design the safety working face and to prevent coal mine fires.

By combining the simulation results of airflows and the tube bundle gas monitoring results, the goaf area can be divided easily into three zones as shown in Figure 10.

\section{Preventing Method for Goaf Fire}

4.1. Injecting Grouting Slurry into Goaf Area. Some effective methods have been studied to prevent fires in the \#3205 working face, such as nitrogen filling, grouting, gelatin injecting, and inhibitor spraying. Their costs and effectiveness were evaluated based on the current conditions of the coal mine, and then the grouting filling method using pulp slurry was chosen as the best method to prevent spontaneous combustion of residual coal in the goaf area. In the grouting filling system, the pulp slurry was transferred by natural hydraulic head between the surface and goafs. The grouting routes are as follows.

Filling station on the surface $\rightarrow$ Ventilation shaft $\rightarrow$ Return airway $\rightarrow$ Concentrated return airway in working face $\rightarrow$ Return airway in working face $\rightarrow$ Goaf area.

The slurry pool $200 \mathrm{~m}^{3}$ in volume was constructed on the level $+32.7 \mathrm{~m}$. The pipes to transport the slurry were vinyl tubes 2.5 inches in diameter. Total length of the slurry pipeline

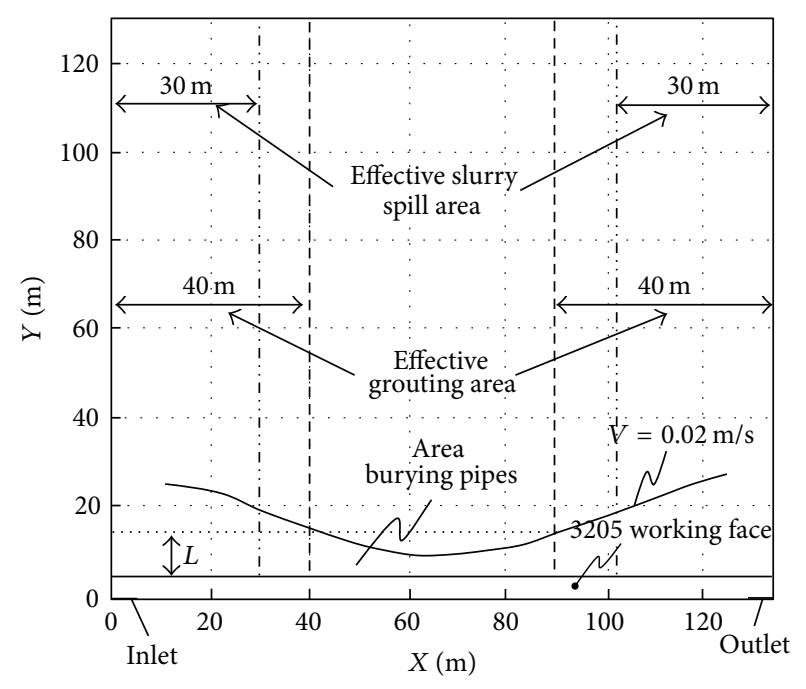

FIGURE 11: Grouting area and pipe bury diagram.

is $L=1994 \mathrm{~m}$ and the vertical level difference is $H=330.7 \mathrm{~m}$; thus the slurry line coefficient is given by $N=L / H=6.03$.

4.2. Grouting Method and Result. The goaf area was filled with grouting slurry to prevent the coal spontaneous combustion of residual coal by installing the pipe end at the position $40 \mathrm{~m}$ away from both ends of the \#3205 working face (see Figure 11). And the distance between the filling area and the working face was controlled to be longer than $10 \mathrm{~m}$, because grouting slurry moved from 15 to $20 \mathrm{~m}$ toward the working face. When a spontaneous combustion is found in the goaf, the working face and goaf area must be spilled with slurry immediately. According to Chinese regulation [25], the slurry spill must cover the area $5 \mathrm{~m}$ away from the working face in the goaf area. To operate grouting slurry to be effective, required amount of solid pulp is given by

$$
Q=K m L H C \text {, }
$$

where $Q$ is amount of solid pulp $\left(\mathrm{m}^{3}\right) ; m$ is coal seam thickness $(m=4.36 \mathrm{~m}) ; L$ is grouting zone strike length $(L=$ $1058 \mathrm{~m}$ ); $C$ is coal recovery ratio, $86 \% ; H$ is grouting zone in clination length $(H=133.7 \mathrm{~m}) ; K$ is grouting coefficient (generally 0.1 to 0.5$),(K=0.3)$.

Also based on the regulation [23], the required amount of water is given by

$$
Q_{w}=K_{w} Q \delta,
$$

where $Q_{w}$ is amount of water, $\left(\mathrm{m}^{3}\right) ; K_{w}$ is coefficient of water reserve ( $=1.10$ to 1.25$) ; \delta$ is water and soil ratio ( $=2$ to 5 , average $\approx 3$ ).

The amount of solid pulp for the goaf area was roughly calculated from (1) as

$$
Q=0.3 \times 4.36 \times 1058 \times 133.7 \times 0.86=159,100\left(\mathrm{~m}^{3}\right)
$$

By substituting above values into (2), the amount of water, $Q_{w}$, was also calculated from (2) as

$$
Q_{w}=1.2 \times 159,000 \times 3=577,600\left(\mathrm{~m}^{3}\right) .
$$




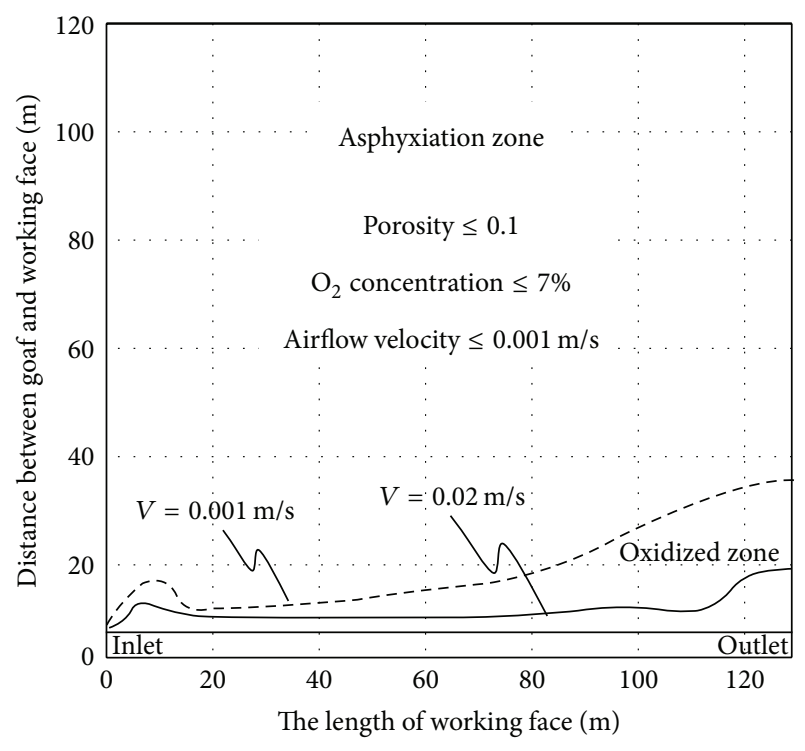

FIGURE 12: Contour lines of air leakage velocity after grouting slurry (goaf porosity is 0.1 ).

Thus, total amount of grouting slurry was calculated as

$$
Q_{T}=Q+Q_{w}=736,700\left(\mathrm{~m}^{3}\right) .
$$

4.3. Grouting Result Simulation Verify. Figure 12 shows the numerical simulation result of velocity contour lines after filling with the grouting slurry by FLUENT. When the goaf is assumed to be filled uniformly with grouting slurry, the oxidation zone exists only in a very small zone just behind the \#3205 working face. This result shows that the slurry grouting is a useful and effective method to prevent the coal spontaneous combustion in the goaf. The area of oxidation zone is affected by porosity in the goaf area. Figure 13 shows the numerical simulation result of the relationship between the area of oxidation zone and goaf porosity. The area increases exponentially with increasing goaf porosity. It shows that filling mined-out goaf area after coal cutting by grouting slurry makes reducing area of oxidation zone and less risk of spontaneous combustion of residual coal in goaf areas. It is also expected that reducing air leakage from the working face by control of ventilation pressure and airflow rate around there is an effective method to prevent spontaneous combustion.

Based on the numerical predictions presented in Figures 12 and 13, the Haizi Colliery applied the slurry grouting in the operation, and the accidents related to spontaneous combustion in the goafs have been not reported.

\section{Conclusions}

In this study, an effective and economical method to prevent spontaneous combustion of residual coal in a goaf area was investigated based on numerical predictions by ventilation simulator MIVENA and flow simulator FLUENT. The characteristics of oxidation and temperature rising in the goaf area

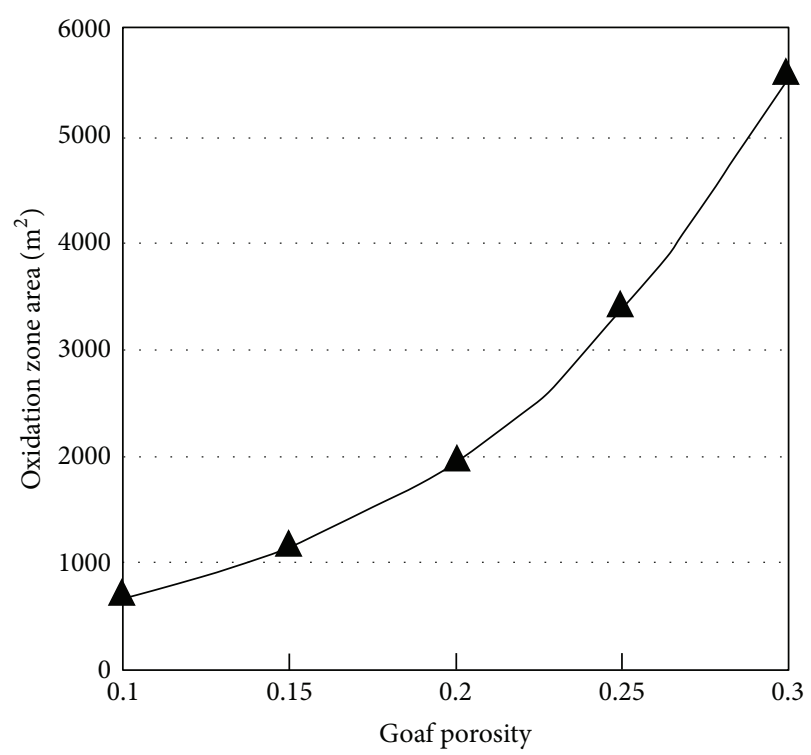

FIGURE 13: Area of oxidation zone versus goaf porosity.

in the Haizi Colliery have been studied by combining the tube bundle gas monitoring results and numerical simulation results. Furthermore, dividing the goaf area into three zones that are radiating, oxidized, and asphyxiation zones, were discussed in considerations of spontaneous combustion of residual coal. It has been cleared that filling porosity in the goaf area by injecting grouting slurry has a function to prevent the coal spontaneous combustion of residual coal in the goaf area.

The present research results are summarized as follows.

(1) The mine ventilation simulator MIVENA was applied to analyze mine ventilation network in the mine, and the flow resistances at the \#3205 working face was controlled to reduce air leakage into goaf area based on the simulation results.

(2) The \#3205 goaf area has been successfully divided into three zones in considering oxygen concentration and air leakage velocity by combining the tube bundle gas monitoring data and numerical simulation results by flow simulator FLUENT.

(3) It has been cleared that slurry grouting is the most economical and effective method to prevent coal spontaneous combustion of residual coal in the goaf area by reducing goaf porosity and also area of oxidation zone behind the working face.

\section{Conflict of Interests}

None of the authors have any conflict of interests associated with this study, and financial supports listed in the acknowledgement are also not conflicted, because present research was carried out by international cooperation and financial supports. 


\section{Acknowledgment}

This work was supported by JSPS KAKENHI (Grant-in-Aid for Scientific Research-B, Grant no. 25303030). This study was also done as the international cooperated research on coal mining safety, especially spontaneous combustion. Y. Wang thanks Japanese Government (MEXT) and Institute of Engineering and Environment LTU for supporting his study.

\section{References}

[1] China Industry Research, "China Coal Industry Report 2014," 2014, http://www.cir.cn/2014-04/MeiTan-HangYeYanJiuBaoGao650.html.

[2] L.-M. Qi and X.-X. Chen, "Theory analysis on spontaneous combustion zone width in the Middle of Goaf," Procedia Earth and Planetary Science, vol. 1, no. 1, pp. 322-327, 2009, Proceedings of the 6th International Conference on Mining Science and Technology (ICMST '09).

[3] R. Pan, Y. Cheng, M. Yu, C. Lu, and K. Yang, "New technological partition for 'three zones' spontaneous coal combustion in goaf," International Journal of Mining Science and Technology, vol. 23, no. 4, pp. 489-493, 2013.

[4] J. Deng, J. Xu, Y. Zang, and L. Li, "Experimental and numerical analysis on the shortest spontaneous combustion period of coal," Journal of China Coal Society, vol. 3, pp. 69-75, 1999.

[5] P. C. Bowes, Self-Heating: Evaluating and Controlling the Hazards, H.M.S.O., London, UK, 1984.

[6] K. Sasaki and C. Dindiwe, "An integrated mine ventilation simulator "MIVENA Ver.6" with applications," in Proceedings of the North American/Ninth U.S. Mine Ventilation Symposium, pp. 181-188, 2002.

[7] S. Yang, R. Zhang, and Z. Di, "Mechanism analysis of coal spontaneous combustion and flame retard of conventional fire preventing and extinguishing measures," Journal of China Coal Society, vol. 23, no. 6, pp. 576-580, 1998.

[8] State Administration of Coalmine Safety China, Law of The People's Republic of China on Safety in Mines, China Coal Industry Publishing House, Beijing, China, 2011.

[9] B.-T. Qin, Q.-G. Sun, D.-M. Wang, L.-L. Zhang, and Q. Xu, "Analysis and key control technologies to prevent spontaneous coal combustion occurring at a fully mechanized caving face with large obliquity in deep mines," Mining Science and Technology, vol. 19, no. 4, pp. 446-451, 2009.

[10] Y.-G. Wu, J.-M. Wu, D.-P. Zhang, and C.-S. Zhou, "Distribution law of gas and change rule of 'three zones' in the goaf of fully mechanized top-coal caving working face under the continuous nitrogen injection," Journal of the China Coal Society, vol. 36, no. 6, pp. 964-967, 2011.

[11] X. He, R. Zhang, X. Pei, Y. Sun, B. Tong, and H. Huang, "Numerical simulation for determining three zones in the goaf at a fullymechanized coal face," Journal of China University of Mining and Technology, vol. 18, no. 2, pp. 199-203, 2008.

[12] Y. B. Mu, "Spontaneous combustion characteristics and air leakage control technology of half isolated island fully mechanized caving face," Advanced Materials Research, vol. 718-720, pp. 1639-1644, 2013.

[13] K. Sasaki and Y. Sugai, "Equivalent oxidation exposure-time for low temperature spontaneous combustion of coal," in Heat Analysis and Thermodynamic Effects, chapter 11, pp. 235-254, InTech, 2011.
[14] P. Nordon, "A model for the self-heating reaction of coal and char," Fuel, vol. 58, no. 6, pp. 456-464, 1979.

[15] Z. Weishauptová and J. Medek, "Bound forms of methane in the porous system of coal," Fuel, vol. 77, no. 1-2, pp. 71-76, 1998.

[16] A. D. Alexeev, E. V. Ulyanova, and G. P. Starikov, "Latent methane in fossil coals," Fuel, vol. 83, no. 10, pp. 1407-1411, 2004.

[17] Z. Li, Y. Wang, N. Song, and Y. Yang, "Experiment study of model compound oxidation on spontaneous combustion of coal," Procedia Earth and Planetary Science, vol. 1, pp. 123-129, 2009.

[18] B. Moghtaderi, B. Z. Dlugogorski, and E. M. Kennedy, "Effects of wind flow on self-heating characteristics of coal stockpiles," Process Safety and Environmental Protection, vol. 78, no. 6, pp. 445-453, 2000.

[19] Z.-X. Li, Z.-L. Lu, and Q. Wu, "Numerical simulation study of Goaf methane drainage and spontaneous combustion coupling," Journal of China University of Mining and Technology, vol. 17, no. 4, pp. 503-507, 2007.

[20] K. Brooks and D. Glasser, "A simplified model of spontaneous combustion in coal stockpiles," Fuel, vol. 65, no. 8, pp. 1035-1041, 1986.

[21] J. Gao and H. Wang, "Influence of permeability distribution on airflow field of leakage in gob," China Safety Science Journal, vol. 20, no. 3, pp. 81-85, 2010.

[22] W. Ren, Y. Zhao, and Z. Feng, "Namerical simulation of flow field in Goaf based on FLUENT," Safety in Coal Mines, vol. 44, no. 6, pp. 26-29, 2013.

[23] Y. Zhao, J. Zhang, C.-L. Chou et al., "Trace element emissions from spontaneous combustion of gob piles in coal mines, Shanxi, China," International Journal of Coal Geology, vol. 73, no. 1, pp. 52-62, 2008.

[24] Z. Q. Lan and G. S. Zhang, "Numerical simulation of gas concentration field in multi-source and multi-congruence goaf," Journal of the China Coal Society, vol. 32, no. 4, pp. 396-401, 2007.

[25] State Administration of Coalmine Safety China, Technical Specification of Fire Fighting by Grouting in Coal Mines MT/T 702-1997, Standards Press of China, Beijing, China, 1998. 

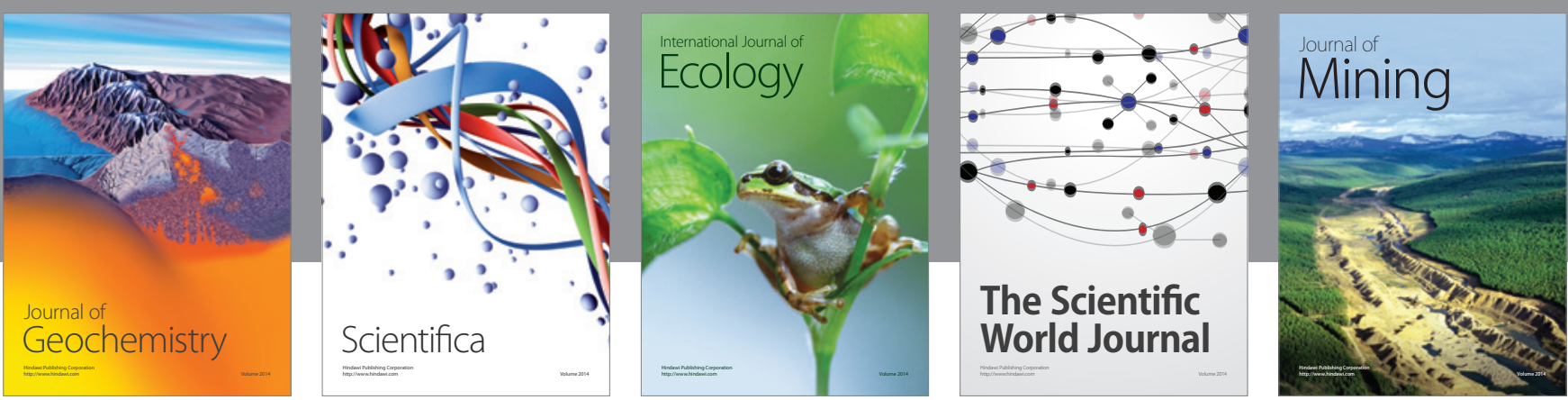

The Scientific World Journal
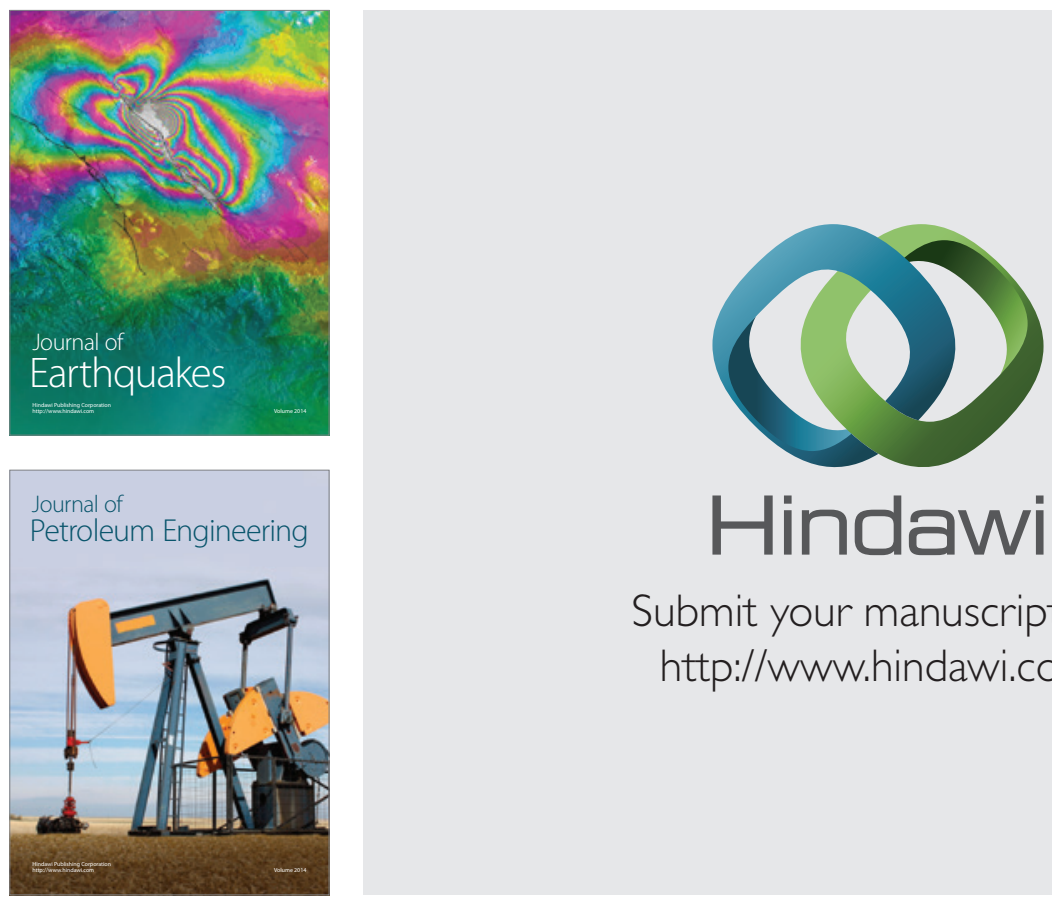

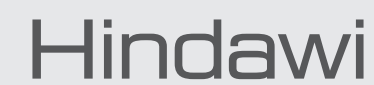

Submit your manuscripts at

http://www.hindawi.com
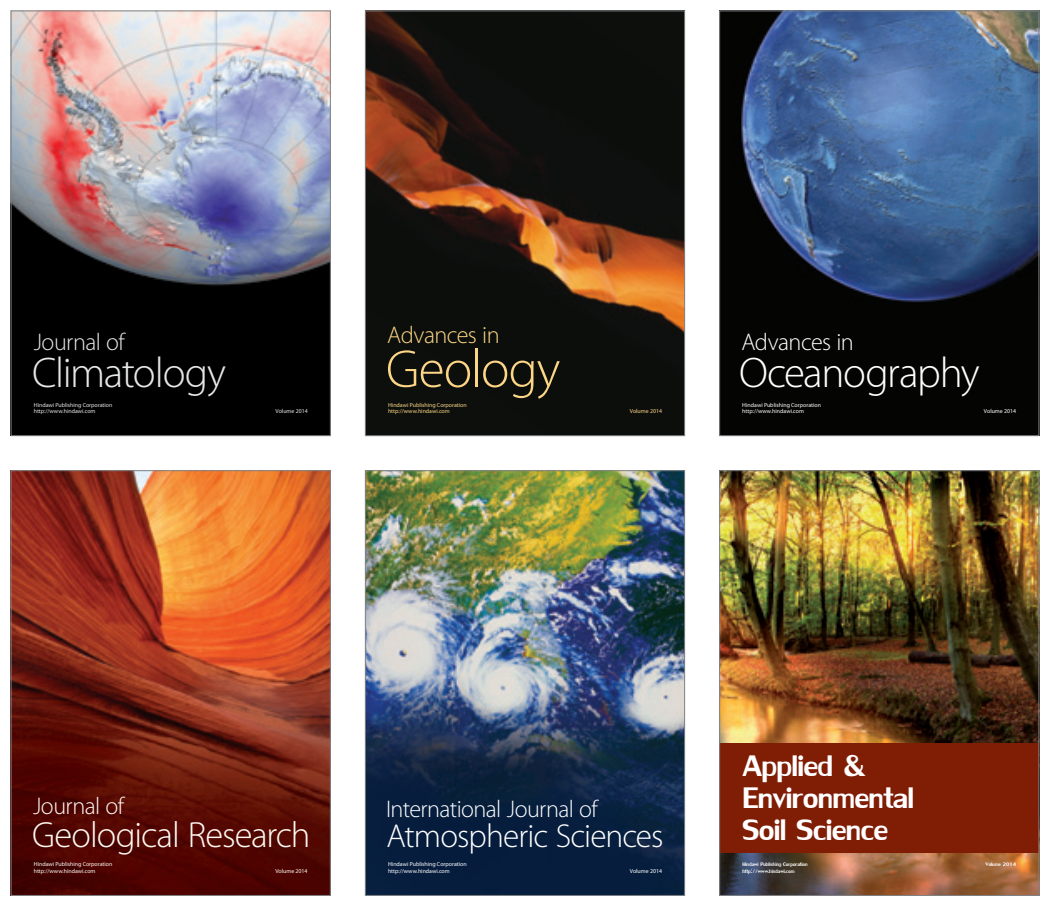
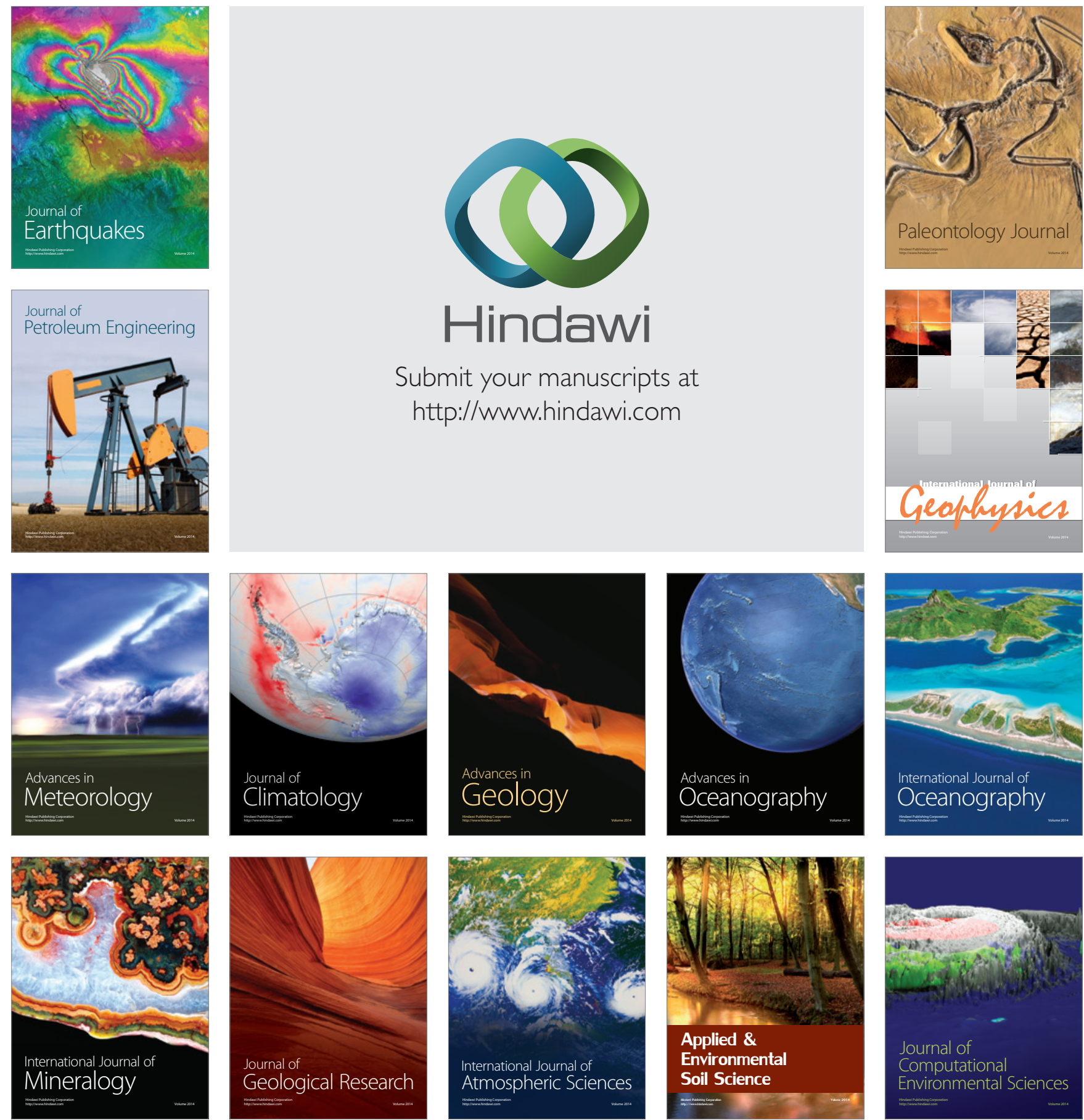